Discussion

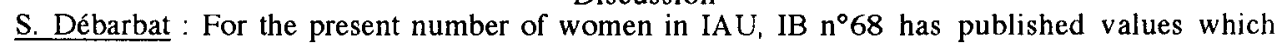
allowed to classify the countries according to the percentage of women among IAU members. At the beginning are, surprisingly, countries from latin origin located in the southern part of Europe followed by a group of anglo-saxon countries. At the end India and Japan

\title{
A CALL FOR INDIRECT SOURCES TO SERVE FOR THE HISTORY OF THE IAU
} Suzanne Débarbat, Observatoire de Paris, France

The history of the IAU produced by Adriaan Blaauw, has shown the difficulties he encountered for the very first years of the Union. From the oral tradition, at the Paris Observatory where I work from 1953, it was said that these IAU archives were in Belgium. After I passed this information to Adrian Blaauw he made an enquiry in the direction of our colleagues from the Royal Observatory in Brussels. Their answer was that there are no such archives in this Observatory ; it was also said that nobody there knows where they could be. For his research on the history of the IAU, Adrian Blaauw used archives, among other papers, from the Paris Observatory, recently available under the usual rules, from the time Benjamin Baillaud was the director of the Paris Observatory (1907-1929) ; they include the years of discussion and creation of the international unions after World War I.

A call is made to astronomers, historians of astronomy and any person related to this subject to look at any possibility in their home country to host archives related to the beginning of the IAU. Another call is made to any person related to astronomy to look in any archives and to check if they could contain documents concerning the IAU. But there are other possibilities to improve our knowledge about the IAU and its beginning ; it is possible to try to list some items on the subject : archives from people having played a rôle at the beginning of the Union; archives from persons of the same epoch who could have mentioned the subject; private papers or documents in hands of heirs of persons mentioned previously ; articles published in local magazines, newspapers, ... in towns or provinces from which these persons originate ; articles published in amateur or large public magazines ; biographies on given persons and generally speaking what is called grey litterature ;...

As a conclusion I would say that direct sources are important as well as indirect sources to contribute to the history of the IAU and I have a question : Do we have to propose a resolution on the search of archives in any observatory or astronomical institution to call attention of people on the subject and also on the importance of archives in any case ?

\section{A. Blaauw asks E. Müller (past GS) to speak on the subject.}

E. Müller : During my time as IAU General Secretary (1976-1979) it was decided that the IAU secretariat should have a permanent place rather than to have to move every three years to the place of the General Secretary. At that permanent place all IAU documents including all archives from the very first 
years of the IAU were collected. During my time as General Secretary I had correspondence with Prof. Velghe in Brussels (Belgium) and Prof. Brumba at Ondrejov (Czechoslovakia) concerning the IAU archives which were deposited in these two observatories. When at the end of 1979 the permanent secretariat of the IAU was settled at the Observatoire de Paris the archives of the IAU were shipped from Brussels, Ondrejov and Lausanne/Geneva to Paris where they were stored at the little house near the entrance of the Paris Observatory. In later years, when the IAU secretariat was moved to the "Institut d'Astrophysique de Paris" (IAP), the IAU archives were also moved to the Institute where they are probably still be stored.

P. Wayman: In 1979-1982 the IAU Archives were in reasonable order and could be consulted. They were still in the same order in the basement of the IAU house when I left.

S. Débarbat : I went recently to the basement of the little house and I can insure that it is empty, which is normal after the IAU secretariat was moved to the IAP building.

\section{EARLY GENERAL SECRETARIES AND THE IAU HISTORICAL ARCHIVES}

Adriaan Blaauw, Kapteyn Laboratory, Groningen, Netherlands

First General Secretaries. The Union's first General Secretary (19191925) was Alfred Fowler of Imperial College, London, the second one (19251935) was F.J.M. Stratton of Cambridge, the third one (1935-1948) J.H. Oort of Leiden, the fourth one (1948-1952) B.G.D. Strömgren, first at Copenhagen, then at Yerkes Observatory, Williams Bay, USA, and the fifth one P.Th. Oosterhoff (1952-1958) of Leiden. All of them served the Union with great devotion. Important archival data for historical research has been preserved from all of them except from Stratton, whose highly efficient handling of the IAU affairs is reported to have implied strong preference for the waste basket. Among the most interesting items left is Fowler's Notebook, which contains his minutes of the first meeting of the IAU Executive Committee, of July 28, 1919.

The IAU Historical Archives. IAU Historical Archives as such, separate from the Secretarial files and properly inventoried, did not exist when the author undertook writing his "History of the IAU" published in July 1994, but a rich body of documents had been accumulated at the General Secretariat, including also some archives left by IAU Presidents. Up to the year 1980, when the Bureau at Paris was established, these archives had a somewhat nomadic existence, moving with the domicile of the Secretary, except for a part of the collection temporarily stored at Uccle Observatory. (We are indebted to former General Secretary Edith Müller for clarification on this latter point.). Most of the material pertaining to the first three decades, up to and including Gen. Secr. Strömgren, and part of the fourth and fifth one (Secretaries Oosterhoff, Sadler and Pecker) have now been incorporated into provisional, ordered, IAU Archives and an Inventory has been made, sufficient for global referencing, as described in the "History". Steps to be taken now are: a) Arrangements with a suitable host for the Archives, ensuring adequate supervision and protection by storage under proper conditions of 